Research Article

\title{
Experimental Study on the Active Earth Pressure of Narrow Cohesionless Backfills against Rigid Retaining Wall under the Translation Mode
}

\author{
Li-Wei Xu $\mathbb{D D}^{1,2,3}$ and Yu-Jian Lin $\mathbb{D D}^{2}$ \\ ${ }^{1}$ College of Civil Engineering, Fujian University of Technology, Fuzhou, China \\ ${ }^{2}$ College of Civil and Engineering, Fuzhou University, Fuzhou, China \\ ${ }^{3}$ Fujian Provincial Key Laboratory of Advanced Technology and Informatization in Civil Engineering, \\ Fujian University of Technology, Fuzhou, China \\ Correspondence should be addressed to Yu-Jian Lin; phdlinyj@163.com
}

Received 13 June 2020; Revised 24 October 2020; Accepted 30 October 2020; Published 16 November 2020

Academic Editor: Jia-Wen Zhou

Copyright (C) $2020 \mathrm{Li}-\mathrm{Wei} \mathrm{Xu}$ and Yu-Jian Lin. This is an open access article distributed under the Creative Commons Attribution License, which permits unrestricted use, distribution, and reproduction in any medium, provided the original work is properly cited.

\begin{abstract}
In engineering, the new retaining walls are often constructed near the existing structure owing to the space limitation. The backfill behind the retaining wall is narrow, which causes an overestimation in the active earth pressure by using Coulomb's earth pressure theory. In previous studies, experimental observations for the failure modes of narrow backfills are still rare. To confirm the failure mode of the narrow backfill, the experimental method and the geotechnical particle image velocimetry method are employed to observe the active failure process of the cohesionless narrow backfill with various widths under the translation mode. The experimental results revealed that the decrease in the length of the backfill width led to the increase in the inclined angle of the sliding surface. When the backfill width was sufficiently small, the sliding surface developed from the wall toe to another wall face, and then another sliding surface occurred as a reflection. In addition, the active earth pressure of the narrow backfill is significantly smaller than that calculated using Coulomb's method. The active failure calculation models are established based on the experimental results. The active earth pressure of the narrow cohesionless backfill under the translation mode is derived by using the limit equilibrium methods. The proposed method was validated by comparing with the previous method and the experimental data.
\end{abstract}

\section{Introduction}

To be able to cope with the growth of infrastructure, new structures are often inevitably constructed adjacent to the existing ones (e.g., slope protection, mountain highway, and sheet-pile wharf, Figure 1). There are often some cases in which the backfill behind the retaining wall is narrow. In such cases, the basic assumption that 'the backfill behind the retaining wall is semi-infinite' is no longer satisfied; thus, the classical theories $[1,2]$ cannot exactly predict the earth pressure and failure mode for the narrow backfill. Compared with the semi-infinite soil, the narrow soil was found to be affected by another boundary constraint (e.g., rock face, basement wall and another existing structure) and the retaining wall. The failure mode of the narrow backfill is still unclear.

Numerous researchers judged that when the backfill width was sufficiently small, the principal stress would rotate, and a complete soil arching would develop due to the soil-wall interface friction on two sides. Thus, based on the soil arching theory, the horizontal slice limit equilibrium method could be employed to calculate the earth pressure of the narrow backfill. Handy [3] first cited the effect of soil arching on the active earth pressure of backfill between vertical parallel walls. Frydman and Keissar [4] measured the active earth pressure of the narrow backfill by controlling the movement of the retaining wall in the centrifuge model tests. Based on the test results, they enhanced the formula of 


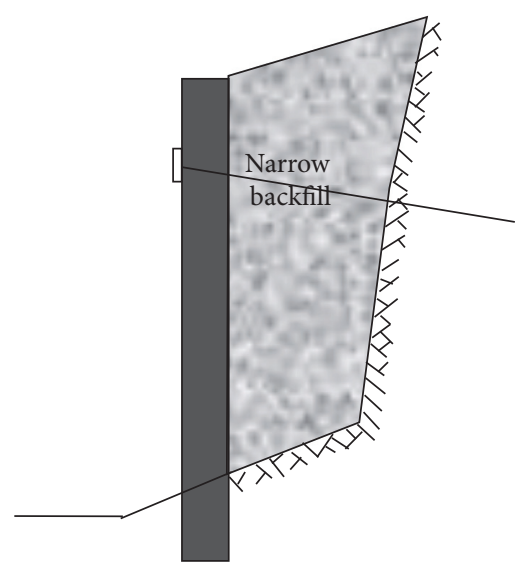

(a)

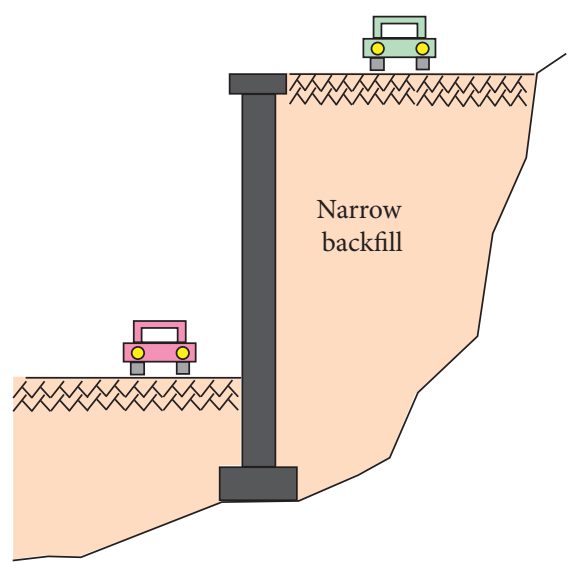

(b)

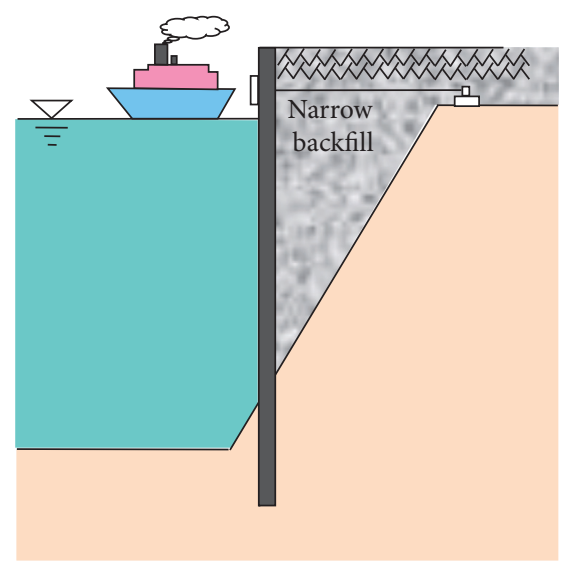

(c)

FIGURE 1: Narrow backfill in engineering. (a) Slope protection. (b) Mountain highway. (c) Sheet-pile wharf.

Handy [3] and defined the relationship between the lateral earth pressure coefficient and internal and external frictions. Valsangkar [5] measured the earth pressure of the narrow backfill at rest with various widths using the centrifuge model tests. As a result, the narrow backfill at rest had a significantly less earth pressure than the semi-infinite soil. Moreover, the Earth pressure decreased with the decrease in the backfill width. The calculation methods considering the effect of soil arching were agreed with tests. In recent years, the failure mechanism of the narrow backfill has been the focused of research. Khosravi et al. [6] observed the displacement field of the narrow backfill under the translation mode by using geotechnical Particle Image Velocimetry (GeoPIV). It was found that the sliding surface in the narrow backfill developed from the retaining wall toe to the other side wall face and that the failure wedge was a right trapezoid. Yang and Tang [7] employed the method of layering sand in various colours to locate the sliding surface. They also investigated the active failure mode of the narrow backfill with different wall displacement modes. They assumed that the sliding surface in the narrow backfill was a smooth curve, which was influenced by the backfill width and wall displacement modes. The studies previously mentioned experimented with the failure mode of the narrow backfill and observed the form of the failure wedge. However, the deformation and stress state in the failure wedge could not be neglected. Greco [8] assumed that multiple sliding surfaces occur in the narrow backfill and that the failure wedge contains several small sliding wedges. Yang et al. [9] compared the results of the numerical simulation and centrifugal model test. They concluded that when the backfill was in the failure state, cracks occurred at the soil-wall interface, which led to the redistribution of soils stress following backfill leakage. Ying et al. [10] simulated the active failure of the narrow backfill using the ABAQUS software. They found that the sliding surfaces that developed in the backfill were in a cross reflection type and that the number of the sliding surfaces was related to the aspect ratio of the backfill. Chen et al. [11] investigated the failure modes of the narrow backfill under various soil-wall interface frictions and backfill widths via limit analysis using the OptumG2 software. They judged that the number of reflection sliding surfaces was also related to the strength of the soil-wall interface. When the strength of the soil-wall interface was weak, the sliding surface would develop along the soil-wall interface rather than generating a new reflection.

To sum up, the failure mode of the narrow backfill is influenced by the backfill width and soil-wall interface friction. In previous studies, the perception of the failure mode of the narrow backfill was almost built on numerical simulations and intuitive experimental phenomena. So far, deep experimentation has not yet been conducted to elucidate the failure mode of the narrow backfill. In this study, a system with the visible retaining wall model and a geotechnical particle image velocimetry method (GeoPIV) is applied to observe the active failure process of the cohesionless narrow backfill with various widths under the translation mode. Based on experimental results, a simple method is proposed to calculate the active Earth pressure of the cohesionless narrow backfill.

\section{Experimental Program}

2.1. Design of the Experimental System. The experimental system consists of four parts: a visual model box, a mobile retaining wall, a light-emitting diode (LED), and a highdefinition (HD) camera. As presented in Figure 2, the frame and body of the model box are welded with $0.8 \mathrm{~mm}$ steel plates, angle irons, and channel steels. The inside dimension of the box is $800 \mathrm{~mm}(L) \times 400 \mathrm{~mm}(H) \times 200 \mathrm{~mm}(W)$. The baseboard is roughened to prevent the relative displacement of soil particles with the baseboard. A $10 \mathrm{~mm}$ thick transparent glass plate is installed on the front of the model box to realise the real-time observation of soil deformation during the tests. To simulate various backfill widths, a detachable rigid wall is set on the right side of the backfill in the model box, which can be fixed by slots. A movable retaining wall $[300 \mathrm{~mm}(H) \times 200 \mathrm{~mm}(W) \times 80 \mathrm{~mm}(T)]$ is set on the left side of the backfill, which is installed using a screw and driven by an alternating current (AC) motor to control the 


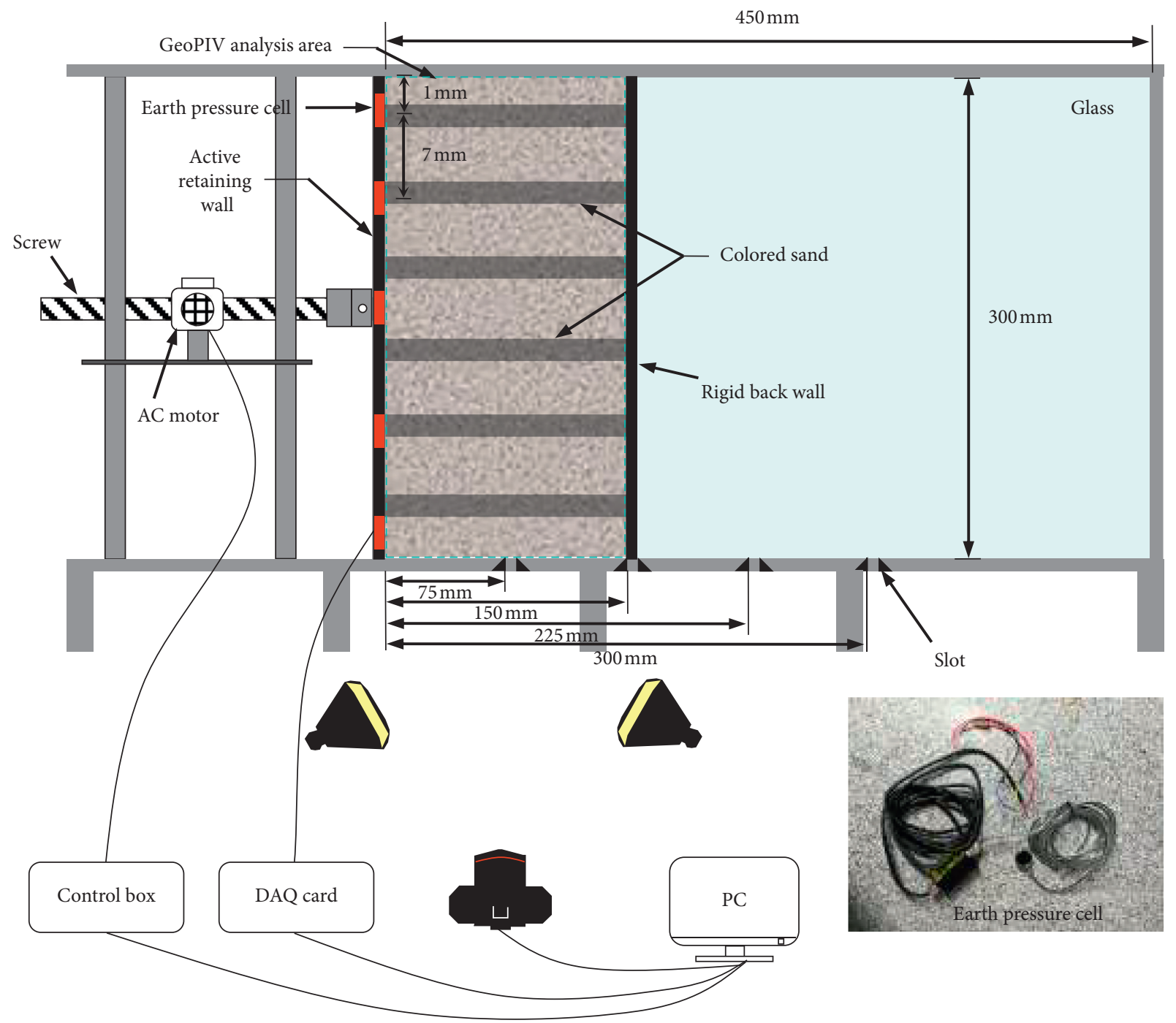

FIgURe 2: Experimental system.

movement of the wall translation. To monitor the distribution of the lateral earth pressure along the retaining wall, five earth pressure cells are installed at various depths and along the central line of the retaining wall. Through a data acquisition (DAQ) card, the earth pressure cells are connected to the computer. Moreover, soft wool strips are utilised at the joints of the retaining walls and model box to prevent sand leakage and reduce the friction. An HD camera and a LED are installed on the front of the model box. Then, a camera is connected to the computer, which records the whole process of soil deformation by taking pictures at intervals.

2.2. GeoPIV. After capturing a series of test images using the HD camera, the image data are processed using the GeoPIV analysis software. Figure 3 presents the schematic diagram of GeoPIV.

The analysis area needs to be selected first, and the initial mesh should be drawn. Then, the correlation between the analysis area and search area is evaluated, and the position of the deformed point is determined. The deformation field of soils can be calculated from the points with the highest correlation.

2.3. Backfill Material. The backfill material utilised in this experiment is cohesionless soils. The soil parameters measured via laboratory tests are presented in Table 1.

2.4. Design of the Experiment. In Coulomb's [1] earth pressure theory, it is assumed that the backfill behind the retaining wall is a semi-infinite soil and that the sliding surface has developed from the wall toe to the ground. The inclination of sliding surface $\alpha$ can be obtained as follows:

$$
\alpha=\arctan \left[\sqrt{\tan ^{2} \varphi+\frac{\tan \varphi}{\tan (\varphi+\delta)}}+\tan \varphi\right] .
$$

From the previous studies, it can be concluded that the sliding surface of the narrow backfill changes with different boundary conditions. Moreover, the critical point between 


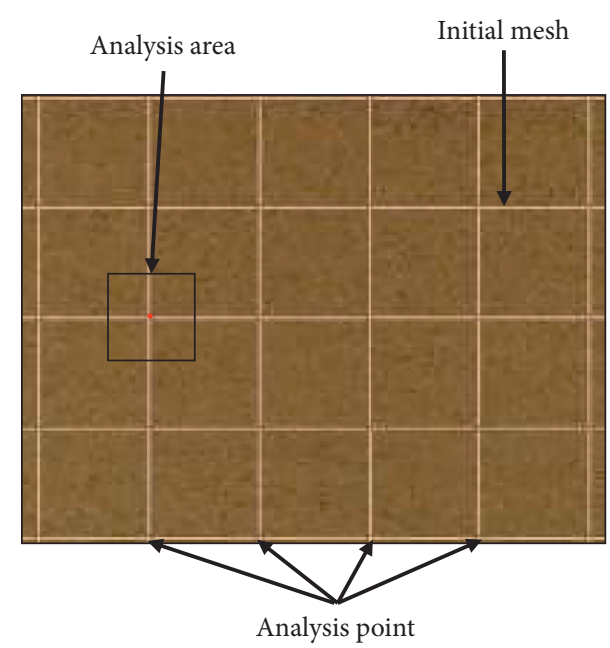

(a)

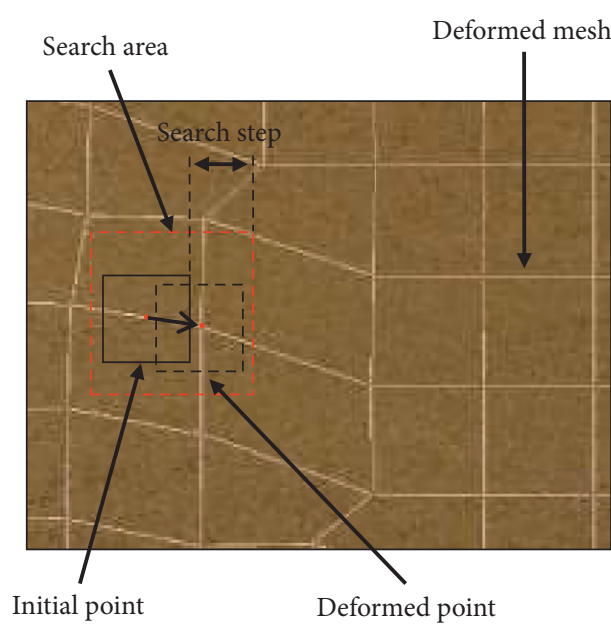

(b)

Figure 3: Schematic diagram of GeoPIV. (a) Initial image. (b) Deformed image.

TABLE 1: Soil parameters.

\begin{tabular}{lcccc}
\hline Diameter $(\mathrm{mm})$ & $\begin{array}{c}\text { Internal } \\
\text { friction } \varphi \\
\left({ }^{\circ}\right)\end{array}$ & $\begin{array}{c}\text { Density } \rho \\
\left(\mathrm{g} / \mathrm{cm}^{3}\right)\end{array}$ & $\begin{array}{c}\text { Void } \\
\text { ratio } e\end{array}$ & $\begin{array}{c}\text { External } \\
\text { friction } \delta\left(^{\circ}\right)\end{array}$ \\
\hline $0.25 \sim 1$ & 30 & 1.488 & 0.64 & 20 \\
\hline
\end{tabular}

'semi-infinite soil' and 'narrow soil' is fuzzy. To determine this critical point and observe the development process of the sliding surface as well as analyse the failure modes and active earth pressure of the narrow backfills, the aspect ratios $B / H$ of the backfill in the tests are set as $2.5,1,0.75,0.5$, and 0.25 .

2.5. Experiment Procedure. The experiment procedure is as follows:

(1) Restore the movable retaining wall to its initial position.

(2) Install the back wall on the slot.

(3) Install the earth pressure cells on the movable retaining wall,

(4) Employ the sand raining technique [12] to fill the model box.

(5) Set the coloured soils on the front of the model to facilitate the determination of the sliding surface during the tests. After filling the soil, allow to sit for 1 day to make it compact under self-weight.

(6) Start the DAQ system and record data after signal stabilisation.

(7) Turn on the interval shooting mode of the camera.

(8) Turn on the AC motor using the control box to drive the movable retaining wall until the backfill has sufficiently deformed.
(9) Continue to collect data for 3 min after the movable retaining wall stops moving.

(10) Turn off all power, and repeat the above steps for the other working conditions.

\section{Experimental Results}

The above experimental methods can facilitate the analysis of the whole deformation process of the backfill soils and observation of the active earth pressure against the retaining wall. To analyse the failure mode of the narrow backfill, the following five typical test groups are selected for discussion.

3.1. Approximate Semi-Infinite Soils. Figure 4 presents the active earth pressure against the retaining wall and the strain contour of soils with the aspect ratio $B / H=2.5$. From Figure 4 , it can be seen that the failure mode obtained using GeoPIV is consistent with Coulomb's [1] theory. The inclined angle of the sliding surface is $60^{\circ}$, which is consistent with the value calculated using Coulomb's [1] theory. In Figure 4, the active earth pressure agrees with the calculated value of Coulomb's [1] theory. This indicates that the backfill $(B / H=2.5)$ is approximately semi-infinite soil. Moreover, it proves that GeoPIV can correctly analyse the soil deformation and show the active failure mode of the backfill.

3.2. Aspect Ratios 1 and 0.75 . Figure 5 presents the active earth pressure against the retaining wall and the strain contour of the narrow backfill $(B / H=1$ and 0.75$)$. The sliding surfaces of both have developed from the wall toe to the ground, and the failure wedge is triangle. However, the inclination of the sliding surface evidently increases with the decrease in the backfill width, compared with the semiinfinite soils. When $B / H=1$, the inclined angle of the sliding surface is $63.30^{\circ}$. Conversely, when $B / H=0.75$, the inclined angle of the sliding surface is $65.62^{\circ}$. Moreover, the 


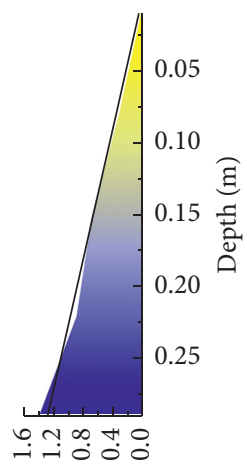

Active earth pressure $(\mathrm{kPa})$

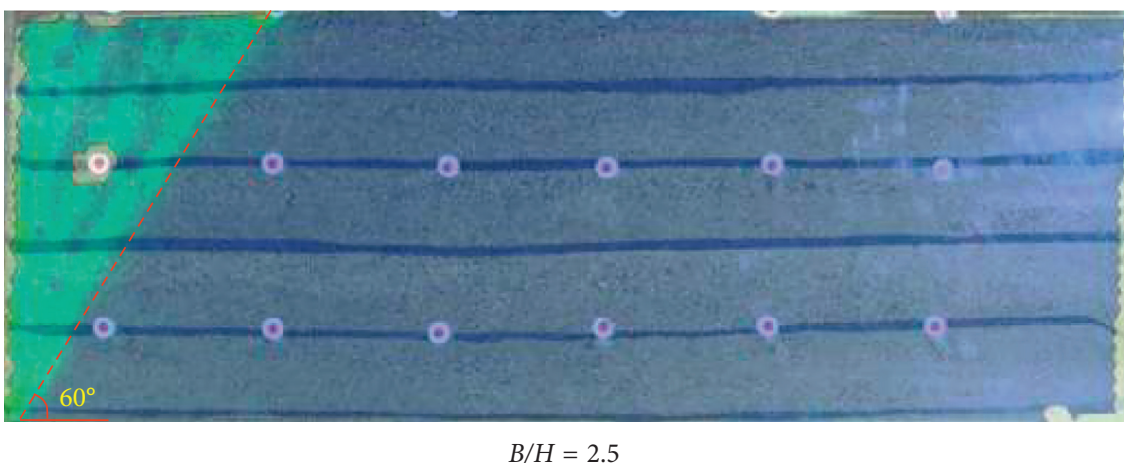

FIGURE 4: Strain contour of approximate semi-infinite soils.
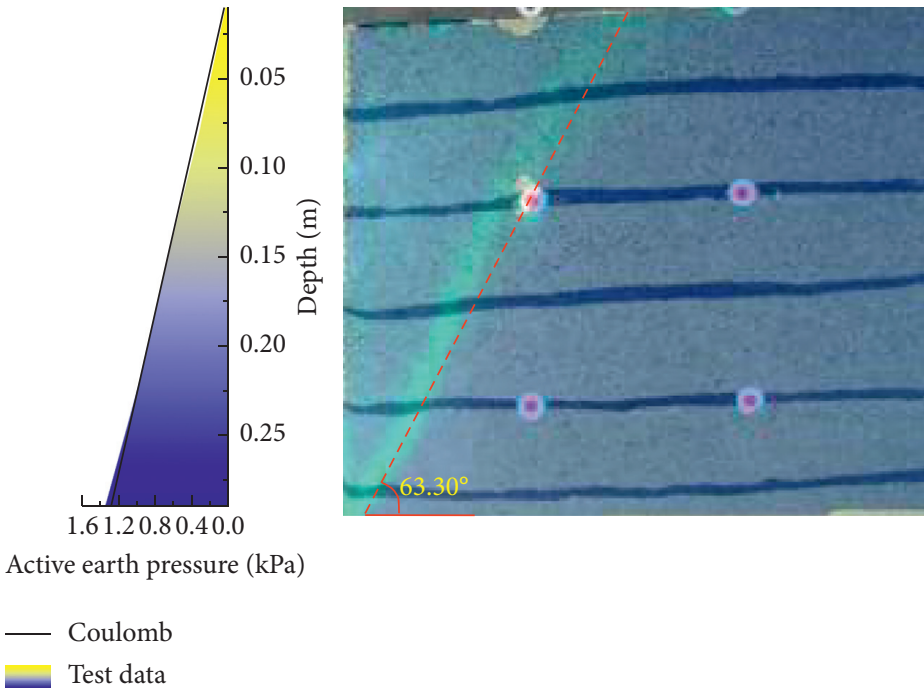

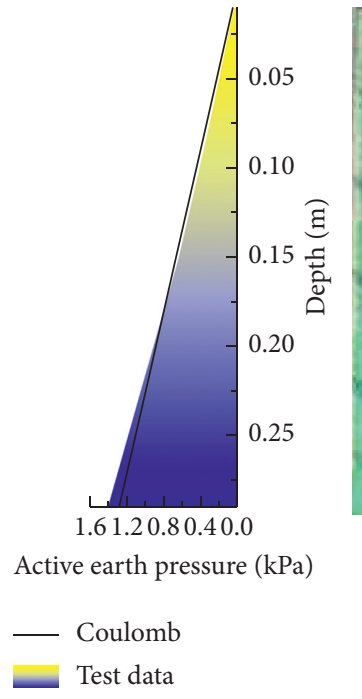

(b)

FIGURE 5: Strain contour of the narrow backfill: (a) $B / H=1$; (b) $B / H=0.75$.

measured data of the active earth pressure are still very close to the Coulomb value.

3.3. Aspect Ratios 0.5 and 0.25 . Figure 6 presents the active earth pressure against the retaining wall and the strain contour of the narrow backfill $(B / H=0.5$ and 0.25$)$. The inclination of the sliding surface further increases with the decrease in the aspect ratio. The inclined angles are $67.69^{\circ}$ and $69.88^{\circ}$, respectively. It is noteworthy that when $B /$ $H=0.25$, the sliding surface develops from the wall toe to another side of the wall face, and then a reflective sliding surface develops to the ground. This phenomenon is consistent with the simulation results of Chen et al. [11]. Moreover, when $B / H$ is sufficiently small, the measured data of the active Earth pressure are significantly less than the Coulomb value.
3.4. BriefSummary. In previous studies, Coulomb [1] theory was often employed to predict the sliding surface inclination of the narrow backfill. The inclination of the sliding surface calculated using Coulomb [1]'s theory was $\alpha=60.03^{\circ}$. According to $\mathrm{Ma}$ et al. [13], the critical point between the 'semi-infinite soil' and 'narrow backfill' can be determined $(B / H=\cot \alpha=0.58)$. However, this critical point is obviously not accuracy. When $B / H=0.5$, the inclined angle of the sliding surface is $67.69^{\circ}$, which is obviously greater than $60.03^{\circ}$. If the classical methods were employed here, the failure area and active earth pressure would be overestimated.

From the comprehensive observation of the strain contours of the narrow backfill with various aspect ratios, it can be deduced that when $B / H>1$, the inclination of the sliding surface of the narrow backfill is consistent with that of the semi-infinite soils. When $B / H \leq 1$, the soil 


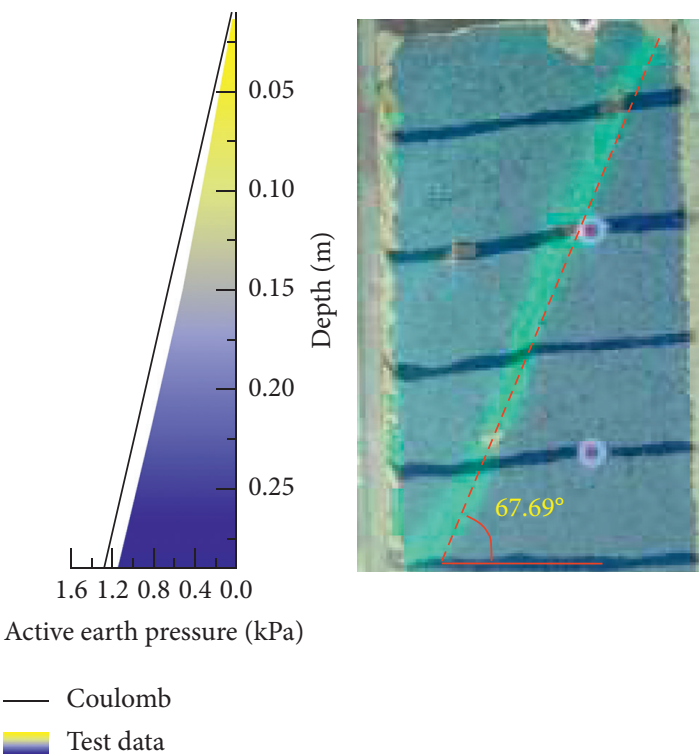

(a)
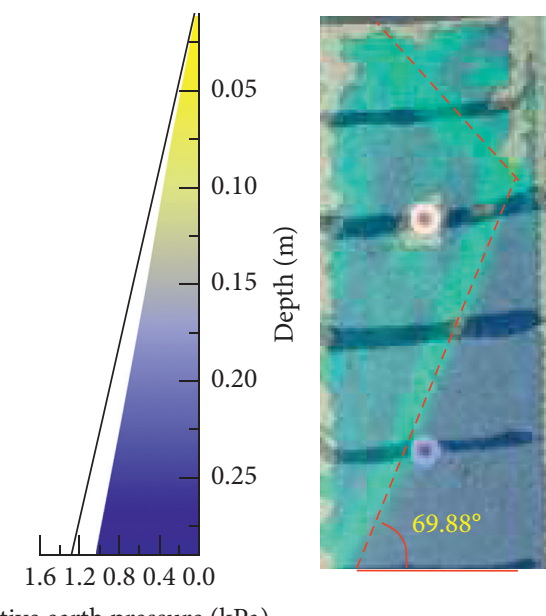

Active earth pressure $(\mathrm{kPa})$

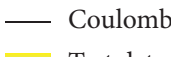

- Test data

(b)

FIGURE 6: Strain contour of the narrow backfill: (a) $B / H=0.5$; (b) $B / H=0.25$.

deformation is constrained by the back wall, and the inclination of the sliding surface increases with the decrease in the aspect ratio of the backfill. Thus, the critical point between the 'semi-infinite soils' and 'narrow backfill' can be determined at the aspect ratio of $B / H=1$. As the aspect ratio of the backfill decreases, the failure mode of the soils experiences three states: (1) the inclination of the sliding surface is consistent with the semi-infinite soils; (2) the inclination of the sliding surface increases with the decrease in the aspect ratio; (3) when the aspect ratio is sufficiently small, the sliding surface develops from the wall toe to the back wall face, and then a reflective sliding surface develops to the ground.

\section{Active Earth Pressure}

Based on experimental results and analysis, simple calculation models are fabricated for the active Earth pressure of the cohesionless narrow backfill under the translation mode. According to the limit equilibrium method, a method for calculating the active Earth pressure of the cohesionless narrow backfill under the translation mode is proposed.

4.1. First Calculation Model. As presented in Figure 7, when the aspect ratio exceeds the critical point, the calculation model is consistent with Coulomb's [1] theory, where $W$ denotes the weight of wedge $A B C ; R$ is the reaction force acting on the sliding surface $A C$; the angle between the direction of $R_{1}$ and the normal of plane $A C$ equals the internal friction angle of the backfill soil $\phi$; and $E$ is the resultant force acting on the wall face; and the angle between the direction of $E$ and the normal of plane $A B$ equals the soilwall interface friction angle $\delta$.

According to the limit equilibrium, the resultant force can be obtained using the following equation:

$$
E=\frac{1}{2} \gamma H^{2} \cot \alpha\left[\frac{\sin (\alpha-\varphi)}{\cos (\delta-\alpha+\varphi)}\right],
$$

where $\gamma$ denotes the unit weight of the backfill.

4.2. Second Calculation Model. As presented in Figure 8, when the aspect ratio is sufficiently small, the sliding surface develops from point $A$ to point $D$, and then a reflective sliding surface develops to point $G$. The contact length between the failure wedge $A B C D$ and the right wall is $\overline{C D}$ :

$$
\overline{C D}=h=H-B \tan \alpha,
$$

where $E_{\mathrm{r}}$ denotes the resultant force acting on the wedge $C D G$, which can be obtained by the first kind of the calculation model.

The external friction of both the side interfaces is assumed as equal, $\delta$. In the wedge $A B C D$, the force equilibrium consists of $W, R, E$, and $E_{\mathrm{r}}$ (Figure 7(b)), where the weight of the wedge $A B C D$ can be obtained using the following equation:

$$
W=\frac{1}{2} \gamma B(H+h)
$$

According to the horizontal force equilibrium,

$$
E \cos \delta=R \sin (\alpha-\varphi)+E_{r} \cos \delta .
$$

According to the vertical force equilibrium,

$$
W=E \sin \delta+R \cos (\alpha-\varphi)+E_{r} \sin \delta .
$$

Combing equations (4)-(6), we gett

$$
E=\frac{W+[\cos \delta \cot (\alpha-\varphi)-\sin \delta] E_{r}}{\cos \delta \cot (\alpha-\varphi)+\sin \delta}
$$




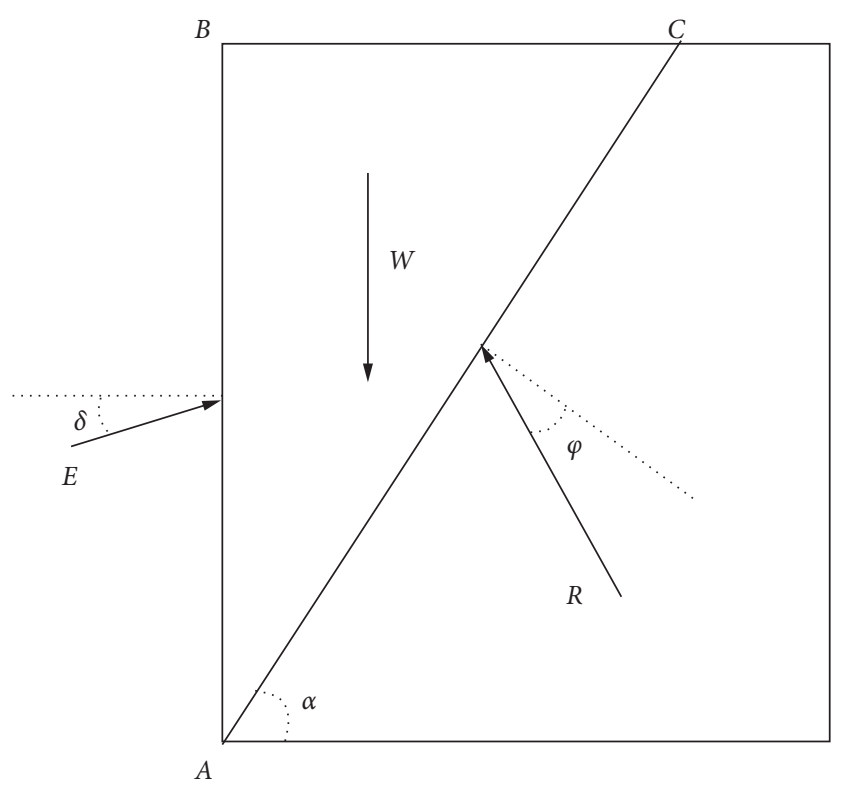

(a)

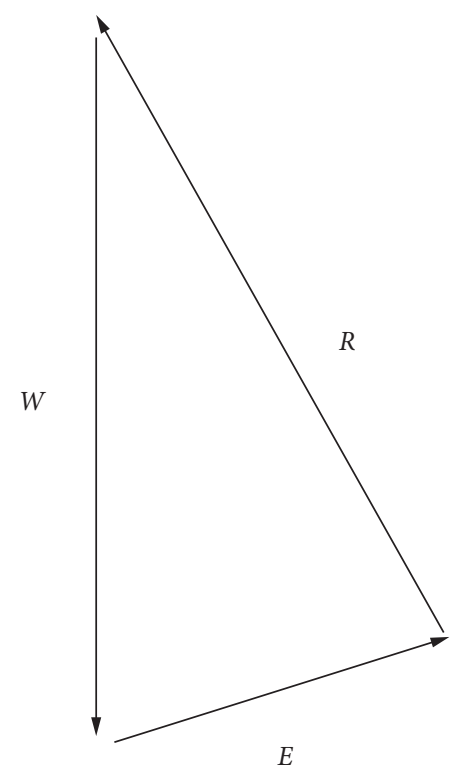

(b)

Figure 7: First calculation model.

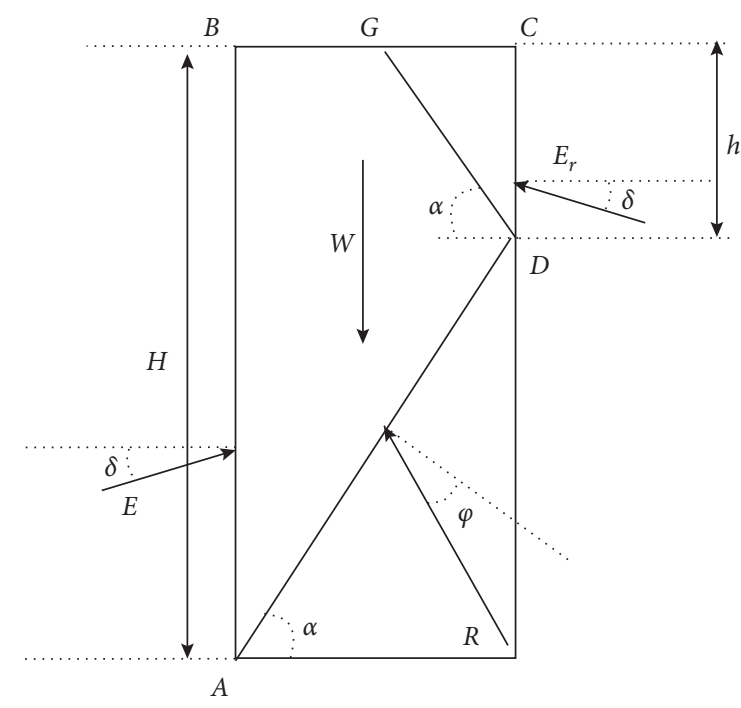

(a)

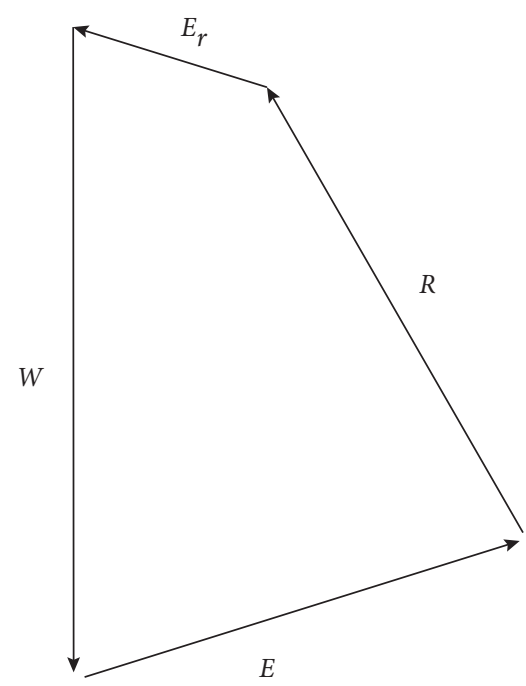

(b)

FIgURE 8: Second calculation model.

4.3. Inclined Angle of the Sliding Surface and Distribution of the Earth Pressure. The resultant of the earth pressure of the narrow backfill can be obtained according to two types of calculation model. It should be noted that $E$ is dependent on the unknown angle $\alpha$ and must be maximised with respect to the angle. The value of $\alpha$ resulting in a maximum for $E$ could be obtained using the following equation:

$$
\frac{\mathrm{d} E}{\mathrm{~d} \alpha}=0 .
$$

Moreover, the active resultant $E_{a}$ and the sliding surface inclined angle $\alpha$ can be confirmed.

The active earth pressure distribution can be obtained using the following equation:

$$
e_{\mathrm{a}}=\frac{\mathrm{d} E_{\mathrm{a}}}{\mathrm{d} z}
$$

where $z$ denotes the calculation depth of the backfill. However, equation (9) is difficult to solve directly. Thus, the finite difference method is employed to convert equation (9): 


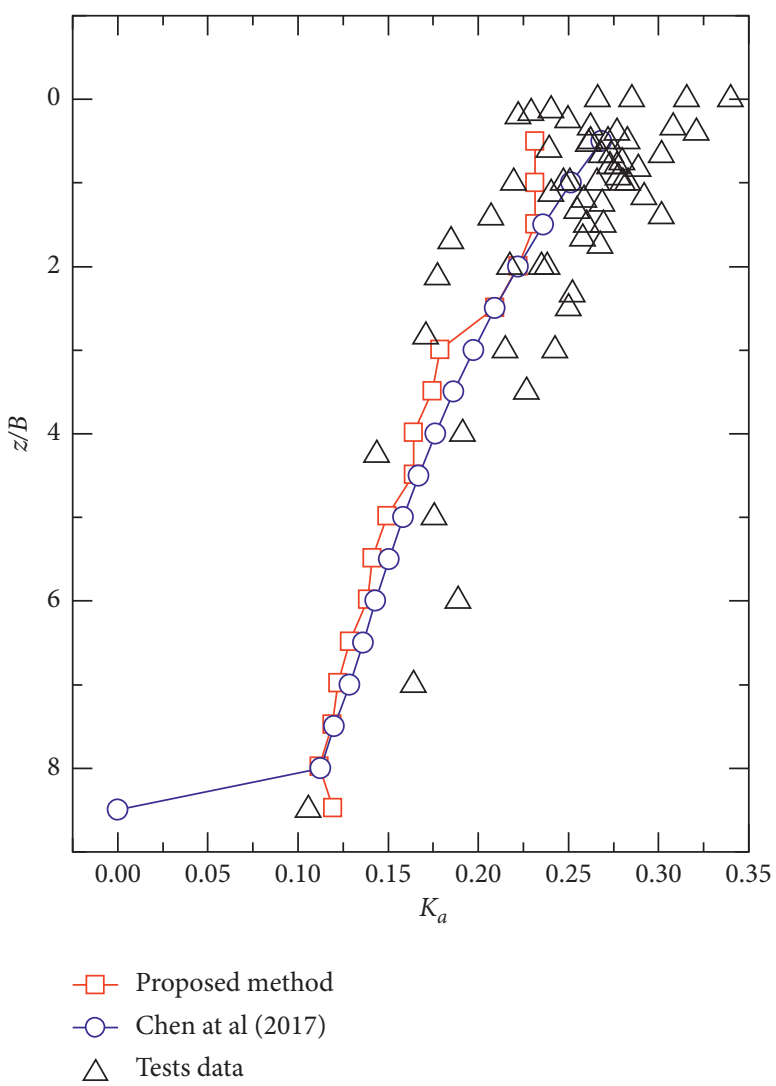

FIgURE 9: Validation of the proposed method.

$$
e_{a \mid \frac{z_{1}+z_{2}}{2}}=\frac{\Delta E_{a}}{\Delta z}=\frac{E_{a \mid z_{2}}-E_{a \mid z_{1}}}{z_{2}-z_{1}}
$$

\section{Validation of the Proposed Method}

To validate the proposed method, the above experimental data are utilised, and the parameters of the retaining walls and backfill soils follow Table 1. In Figure 9, the comparison between the proposed method, the previous method and the experimental data is presented. The proposed method is consistent with them, thus improving its applicability.

\section{Discussion}

In this paper, we show the failure modes of narrow cohesionless backfills through the experimental method and GeoPIV analysis. Compared with previous studies [4-7, 14], our results confirm the existence of reflective sliding surfaces in narrow backfills. This can explain why the distribution of the active earth pressure of the narrow backfills is nonlinear. Different from the previous theoretical analysis that only one sliding surface was considered, the calculation model in this paper is composed of multiple sliding wedges, which is corresponding to the failure mode of narrow backfills and improves the calculation accuracy.

\section{Conclusion}

(1) In this study, the experimental method and GeoPIV method are developed and employed for the measurement of the deformation and active earth pressure of narrow backfills. This experiment is able to effectively record the failure process and earth pressure of the narrow backfills under the translation mode. By using the GeoPIV software for the deformation analysis, the sliding surface position in the backfill can be accurately located, and the failure mode of the narrow backfill can be determined.

(2) Based on the experimental results, the critical point between the 'semi-infinite soils' and 'narrow backfill' can be determined at the aspect ratio of $B / H=1$. As the aspect ratio of the backfill decreases, the sliding surface in soils experiences three states: (1) the inclination of the sliding surface is consistent with the semi-infinite soils; (2) the inclination of the sliding surface increases with the decrease in the aspect ratio; (3) when the aspect ratio is sufficiently small, the sliding surface develops from the wall toe to the back wall face, and then a reflective sliding surface develops to the ground.

(3) Two types of calculation model are developed based on the experimental results. According to the limit equilibrium method, the calculation method for the active earth pressure of the cohesionless narrow backfill under the translation mode is proposed. To verify the applicability of the proposed method, it is compared with the previous method and the experimental data.

\section{Notation}

$B: \quad$ Width of the backfill (m)

$H$ : Depth of the backfill (m)

$h$ : Contact length between the failure wedge and the back wall (m)

$z$ : $\quad$ Depth of the calculation (m)

$B / H$ : Aspect ratio

$\gamma$ : Unit weight of the backfill $\left(\mathrm{kN} / \mathrm{m}^{3}\right)$

$\phi: \quad$ Internal friction angle of the backfill soil $\left({ }^{\circ}\right)$

$\delta$ : $\quad$ Friction angles between the backfill soil and two retaining walls $\left({ }^{\circ}\right)$

$\alpha$ : $\quad$ Inclined angle between the sliding plane and the horizontal line $\left({ }^{\circ}\right)$

$W$ : Weight of the soil $(\mathrm{kN} / \mathrm{m})$

$R: \quad$ Reaction force acting on the sliding plane $(\mathrm{kN} / \mathrm{m})$

$E$ : Resultant acting on the soil $(\mathrm{kN} / \mathrm{m})$

$E_{\mathrm{r}}$ : Resultant acting on the back wall $(\mathrm{kN} / \mathrm{m})$

$E_{a}: \quad$ Resultant of the active earth pressure $(\mathrm{kN} / \mathrm{m})$

$e_{a}$ : Active earth pressure $(\mathrm{kPa})$

$K_{a}$ : Coefficient of the active earth pressure.

\section{Data Availability}

All data used to support the findings of this study are available within the article. 


\section{Conflicts of Interest}

The authors declare that they have no conflicts of interest.

\section{References}

[1] C. A. Coulomb, "Essai sur une application des regles de maximis et minimis a quelques problemes de statique relatifs a l'architecture," Mémoires de mathématique et de physique, presentés à l'Académie royale des sciences, vol. 7, no. 7, pp. 343-382, 1773.

[2] W. J. M. Rankine, "On the stability of loose earth," Proceedings of the Royal Society of London, vol. 147, pp. 9-28, 1857.

[3] R. L. Handy, "The arch in soil arching," Journal of Geotechnical Engineering, vol. 111, no. 3, pp. 302-318, 1985.

[4] S. Frydman and I. Keissar, "Earth pressure on retaining walls near rock faces," Journal of Geotechnical Engineering, vol. 113, no. 6, pp. 586-599, 1987.

[5] W. A. Take and A. J. Valsangkar, "Earth pressures on unyielding retaining walls of narrow backfill width," Canadian Geotechnical Journal, vol. 38, no. 6, pp. 1220-1230, 2001.

[6] M. H. Khosravi, T. Pipatpongsa, and J. Takemura, "Experimental analysis of earth pressure against rigid retaining walls under translation mode," Géotechnique, vol. 63, no. 12, pp. 1020-1028, 2013.

[7] M. H. Yang and X. C. Tang, "Rigid retaining walls with narrow cohesionless backfills under various wall movement modes," International Journal of Geomechanics, vol. 17, no. 11, Article ID 04017098, 2017.

[8] V. Greco, "Active thrust on retaining walls of narrow backfill width," Computers and Geotechnics, vol. 50, no. 3, pp. 66-78, 2013.

[9] K.-H. Yang, J. Ching, and J. G. Zornberg, "Reliability-based design for external stability of narrow mechanically stabilized earth walls: calibration from centrifuge tests," Journal of Geotechnical and Geoenvironmental Engineering, vol. 137, no. 3, pp. 239-253, 2011.

[10] H. W. Ying, D. Huang, and Y. X. Xie, "Study of active earth pressure on retaining wall subject to translation mode considering lateral pressure on adjacent existing basement exterior wall," Chinese Journal of Rock Mechanics and Engineering, vol. 30, no. 1, pp. 2970-2978, 2010, in Chinese.

[11] F. Chen, Y. Lin, and D. Li, "Solution to active earth pressure of narrow cohesionless backfill against rigid retaining walls under translation mode," Soils and Foundations, vol. 59, no. 1, pp. 151-161, 2019.

[12] S. P. G. Madabhushi, N. E. Houghton, and S. K. Haigh, "A new automatic sand pourer for model preparation at University of Cambridge," in Proceedings of the 6th International Conference on Physical Modelling in Geotechnics, pp. 217-222, London, UK, August 2006.

[13] P. Ma, S. Q. Qing, and H. T. Qian, "Calculation of active earth pressure for limited soils," Chinese Journal of Rock Mechanics and Engineering, vol. 27, no. 1, pp. 3070-3074, 2008, in Chinese.

[14] R. Rui, Y.-Q. Ye, J. Han, L. Zhang, and Y.-X. Zhai, "Experimental and theoretical investigations on active earth pressure distributions behind rigid retaining walls with narrow backfill under a translational mode," International Journal of Geomechanics, vol. 20, no. 10, Article ID 04020178, 2020. 